\title{
Comprehensive Characterization of Droughts in Slovakia
}

\author{
M. M. Portela, M. Zeleňáková, J. F. Santos, P. Purcz, A. T. Silva, and H. Hlavatá
}

\begin{abstract}
The results from a comprehensive drought analysis for the entire Slovakia based on the precipitation records at a large number of climatic stations (491) over a considerable span of time ( 33 years) are presented. The study included the definition of homogenous regions regarding the temporal pattern of the droughts (by means of Principal Components Analysis, PCA), the analysis of the frequency of the droughts (based on the Kernel occurrence rate estimation method, KORE, coupled with bootstrap confidence bands) and the definition of minimum precipitation surfaces aiming at the recognition of the drought events at the early stages of their occurrence.
\end{abstract}

Index Terms-Drought, frequency, precipitation thresholds, regionalization, Slovakia.

\section{INTRODUCTION}

The understanding of the droughts and of their characteristics and consequences and the capability of modelling and forecasting their occurrences are major issues to ensure a successfully water resources policy, namely in countries and regions more prone to those extreme hydrological events. These tasks become even more important under climatic change scenarios, especially when decreases of the rainfall and surface flow are expected.

Despite the recurrent nature of the droughts, namely in regions with pronounced hydrological temporal variability, they are among the most relevant and simultaneously the most complex and least understood extreme hydrologic events. Droughts can be perceived as prolonged and regionally extensive occurrences of below average natural water availability [1], either in the form of rainfall, river runoff or groundwater. Unlike other weather disasters, droughts start unnoticeably, develop cumulatively, produce cumulative impacts and by the time damages are visible, it is too late to mitigate their consequences.

Since droughts are regional events, it is important to assess their variability and characteristics within the affected areas.

Manuscript received May 23, 2016; revised July 21, 2016. The research was financed by the Portuguese Fundação para a Ciência e Tecnologia, FCT, by through the project Proc. 441.00 Eslováquia (Transnational Cooperation. Scientific Cooperation Agreement between Portugal and Slovakia) - SRDA SK-PT-0001-012. The authors thank the Slovak Hydrometeorological Institute for providing the precipitation data.

M. M. Portela and A. T. Silva are with the Civil Engineering Departmant, Instituto Superior Técnico, Universidade Técnica de Lisboa, Portugal (e-mail: artur.tiago.silva@técnico.ulisboa.pt). maria.manuela.portela@técnico.ulisboa.pt,

M. Zelenáková is with the Technical University of Košice, Košice, Slovakia (e-mail: martina.zelenakova@tuke.sk).

J. F. Santos is with the Instituto Politécnico de Beja, Beja, Portugal (e-mail: joaofisantos@gmail.com).

P. Purcz is with the Technical University of Košice, Košice, Slovakia (e-mail: pavol.purcz@tuke.sk).

H. Hlvatá is with the Slovak Hydrometeorological, Košice, Slovakia (e-mail: helena.hlavata@shmu.sk).
This paper presents the results of a stepwise and comprehensive analysis of the droughts for the entire Slovakia based on extensive monthly rainfall measurements, kindly provided by the Slovak Hydrometeorological Institute, over a considerable time-span in a large number of climatic stations evenly distributed over that country (Fig. 1): 491 climatic stations with 33 years of precipitation data, from January 1981 to December 2013 [2] and [3].

To achieve the previous purpose one of the most common indexes, the Standardized Precipitation Index (SPI) [4], was selected due to its few data requirements, to the relatively simplicity of its computation when compared to other indices and to its comparability because it is a dimensionless index [5]-[7].

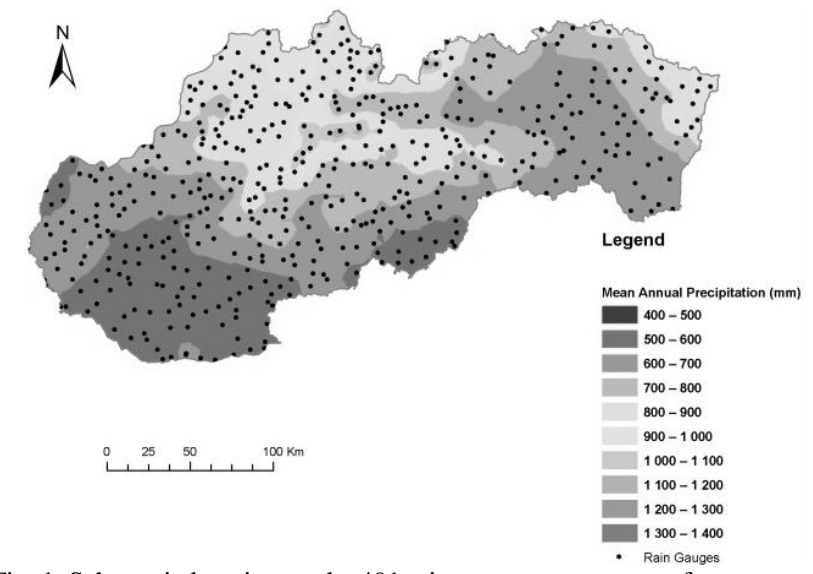

Fig. 1. Schematic location on the 491 rain gauges over a map of mean annual precipitation in Slovakia. Adapted from [2].

The SPI was designed to quantify the precipitation deficit at different time scales (from 1 to 24 months), which reflect the impact of droughts on the different types of reservoirs of fresh water at the watershed level - as the time scale increases, meteorological, agricultural, hydrological and the socio-economic droughts [8]. The time scale adopted in the study was three months (SPI3) as it reflects short- and medium-term soil moisture conditions and provides a seasonal estimation of precipitation, which is quite important in primary agricultural regions such as Slovakia. In fact, approximately half of the country is under agricultural production [9]. The computation of the index at the previous time scale utilized the Pearson type III distribution with parameters estimated by the method of L-moments [10]. Regarding the drought categories, the following scale of SPI values, developed by [11], was adopted: below -1.65 , extreme droughts; between -1.65 and -1.28 , severe droughts; and between -1.28 and -0.84 , moderate droughts.

In Slovakia, as in many other European countries, the fresh water related risk, and specifically the droughts are expected to become more frequent, intense and prolonged due to climate change [12] and [13]. At the same time, most of the studies about the issue are focused on specific regions or 
aspects rather than aiming at a comprehensive characterization of the phenomenon for the whole country, based on extensive hydrological ground data [14]-[20].

This paper presents some of the more relevant results achieved by [2] and [3], namely: a drought regionalization for Slovakia; for each homogenous region the characterization of the yearly frequency of the drought occurrences; and the establishment of surfaces of precipitation thresholds that can be used to identify the droughts at the early stages of their development.

\section{MODELS APPLIED}

Droughts are regional events which makes important to identify areas not only more prone to those occurrences but also where they present similar behavior in terms of main characteristics, such as frequency of occurrence or severity. Having in mind the regional nature of the droughts, prior to the characterization of the phenomenon in Slovakia, an identification of the homogenous areas regarding the temporal pattern of the SPI3 field was done. For that purpose principal component analysis (PCA) was applied, as done by others authors within a similar framework [21], [22] and [5].

To extract the principal components, PCs, the Pearson correlation matrix was considered. The results of PCs were evaluated by analyzing the eigenvalues (interpretation of the scree plot [23]), the correlations between PCs and the original variables (mapping of the factor loadings) and the percentage of the variance explained. To achieve more stable spatial patterns, a rotation of the principal components with the Varimax procedure was done. The patterns defined in this way are referred as rotated principal components, RPCs.

The extracted principle components, either unrotated, PCs, or rotated, RPCs, can be considered representations of the same variable measured in the same units as the SPI3 from which they were derived, which was the assumption underlying the regionalization study.

In what concerns the analysis of the frequency of the droughts in each homogenous region it aimed at ascertaining if regardless of the severity of the drought (i.e., the precipitation deficit) the distribution of the occurrence of droughts changed over time. For this purpose a kernel occurrence rate estimator (KORE) was applied to the historical temporal series of drought occurrences [24]-[27]. Only severe or worse droughts, represented by SPI3 values lower than -1.28 , were considered.

The kernel technique is a nonparametric model developed by [28] for smoothing point process data, in the case of the present application, the times of occurrence of the droughts. A Gaussian kernel was adopted [29]. The KORE analysis used the methodology detailed by [25]-[27] applied to the RPCs obtained from the SPI3 field. To reduce the boundary estimation bias, pseudo data was generated before and after the observation period. To account for the uncertainty of the KORE estimates, a pointwise $90 \%$ confidence band was constructed around the annual occurrence rate or frequency curve by means of a bootstrap simulations [25], [30] and [31]. The previous curve gives the number of events per year, $\lambda(t)$.

Finally SPI surfaces of precipitations thresholds aiming at an expeditious recognition of droughts events were obtained by inversion of the calculation procedures of the SPI3.

\section{RESULTS}

The PCA showed that the first four components explain about $80 \%$ of the total variance of the original SPI3 series and that, from the fourth to the fifth component, the increment of variance explained is negligible (approximately 1\%). By mapping the factor loadings, four leading components were also suggested, since they fully cover the study area and do not overlap. Based on these results, the first four components were retained to rotate.

Fig. 2 contains the maps of the factor loadings thus obtained, i.e., the spatial representation of the correlation, R, between each one of the four rotated components, RPCs, and the SPI3 field data. Based on these results, the regions where $\mathrm{R}$ was equal or higher than 0.6 were delimited, as represented in Fig. 3. For that purpose an area was assigned to each rain gauge, according to the Thiessen polygon method [32]. The Thiessen polygons are also represented in Fig. 3. This figure shows that the procedure applied was able to identify regions that are spatially very well delimited, do not overlap and almost cover the whole Slovakia.

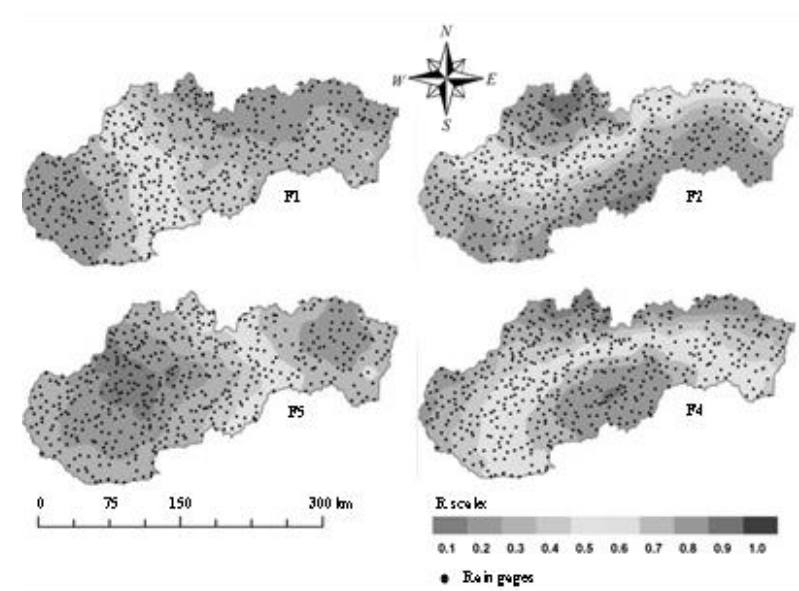

Fig. 2. Spatial correlation maps between each RPC and the at-site SPI3 Adapted from [3].

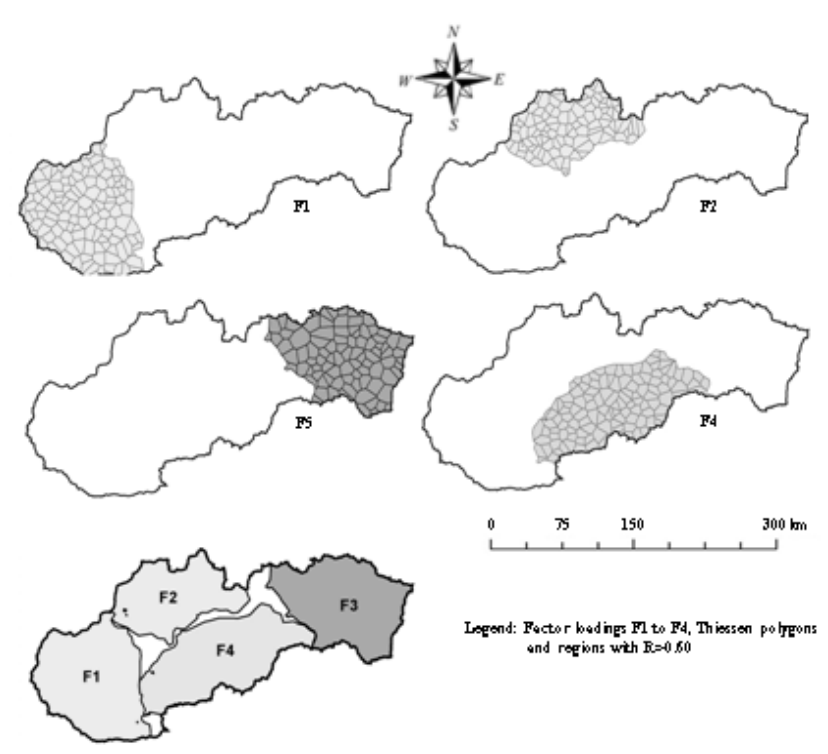

Fig. 3. Regions with correlation coefficient, R, between each rotated principal component and the at-site SPI3 series equal or higher than 0.6 Thiessen polygons for the rain gages included in each homogenous region.

The region of Slovakia highlighted by each RPC, the percentage of the total variance explained by such component and the number of rain gages located inside the region are as 
follows (from the first to the fourth component, denoted by F1 to F4 in Fig. 2 and 3): Western Slovakia, 132 rain gages and 22\%; Central Northern Slovakia, 101 rain gages and 20\%; Eastern Slovakia, 90 rain gages and 15\%; and Central Southern Slovakia, 125 rain gages and $23 \%$. It should be stressed that only 43 from the 491 rain gauges were not included in the homogenous regions established based on the temporal patterns of SPI3. All the rotated components relate mostly positive with the original SPI3 series. Each rotated component means that the variation measured by the SPI3 among the drought/wet conditions across region at a time scale of 3 consecutive months can be explained adequately by that component, rather than by the rain gauges included in the region, which means a clear dimensionality reduction of the SPI3 field.

In Fig. 4 the results from the KORE frequency estimator applied to each one of the first four RPCs time series are presented. As mentioned, only severe or worse droughts, represented by values of SPI3 lower than -1.28, were considered. In the diagrams of the figure the vertical ticks along the $\mathrm{x}$-axis indicate the points in time when occurred the drought events.
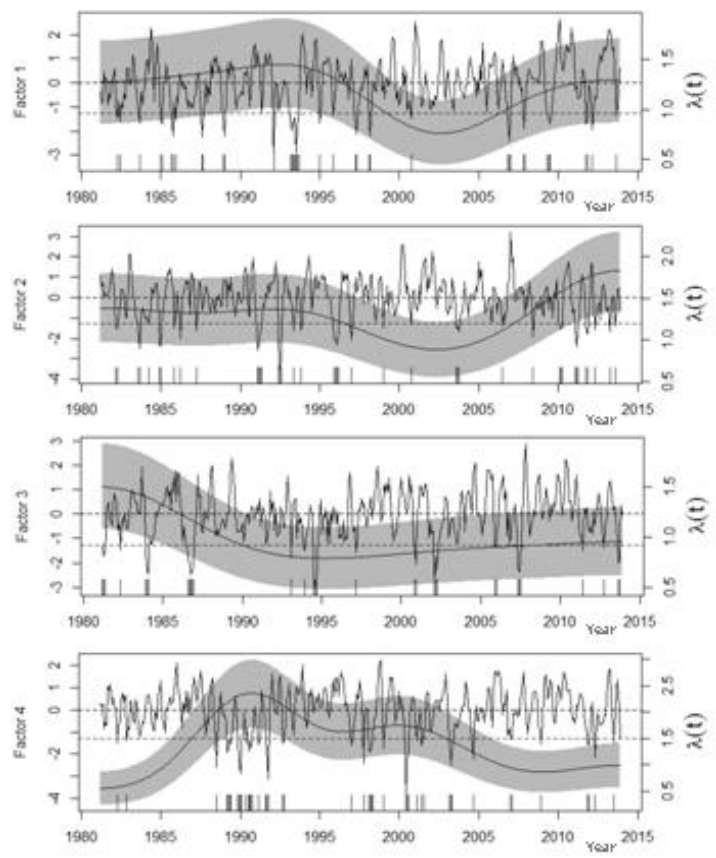

Fig. 4. Time-dependent occurrence rates of severe drought of the 4 RPCs of SPI3 (right). The vertical ticks along $\mathrm{x}$-axis indicate the points in time when drought events occurred. Adapted from [2].

The previous figure shows that the different homogenous regions (identified by the factor loadings) denote different yearly frequencies of occurrence of severe droughts although with some similarity between Western (F1) and Central North (F2) regions, in one hand, and between Eastern (F3) and Central South $(\mathrm{F} 4)$ regions, in the other hand. In fact, the Western half of Slovakia (F1) experienced an increase in the drought occurrences from about 2002 on. Such increase is much more pronounced in the Central North region (F2), where the highest rate of annual droughts occurs at the end of the analyzed period, than in the Western region, where the highest rate of droughts was achieved around 1994, being slightly higher than the rates towards the present. In the Eastern part of Slovakia (F3) the drought frequency seems to be decreasing towards the present or, at least, it is not as high as it was in the past. Except for Central Northern region (F2), all the other regions experienced more frequent droughts in the past, which somehow disagrees with the expected effects of the climate change.

Fig. 5 and 6 exemplifies the precipitation surfaces obtained by inverting the SPI3 for severe and extreme drought categories in each one of the 491 rain gauges used in the study.

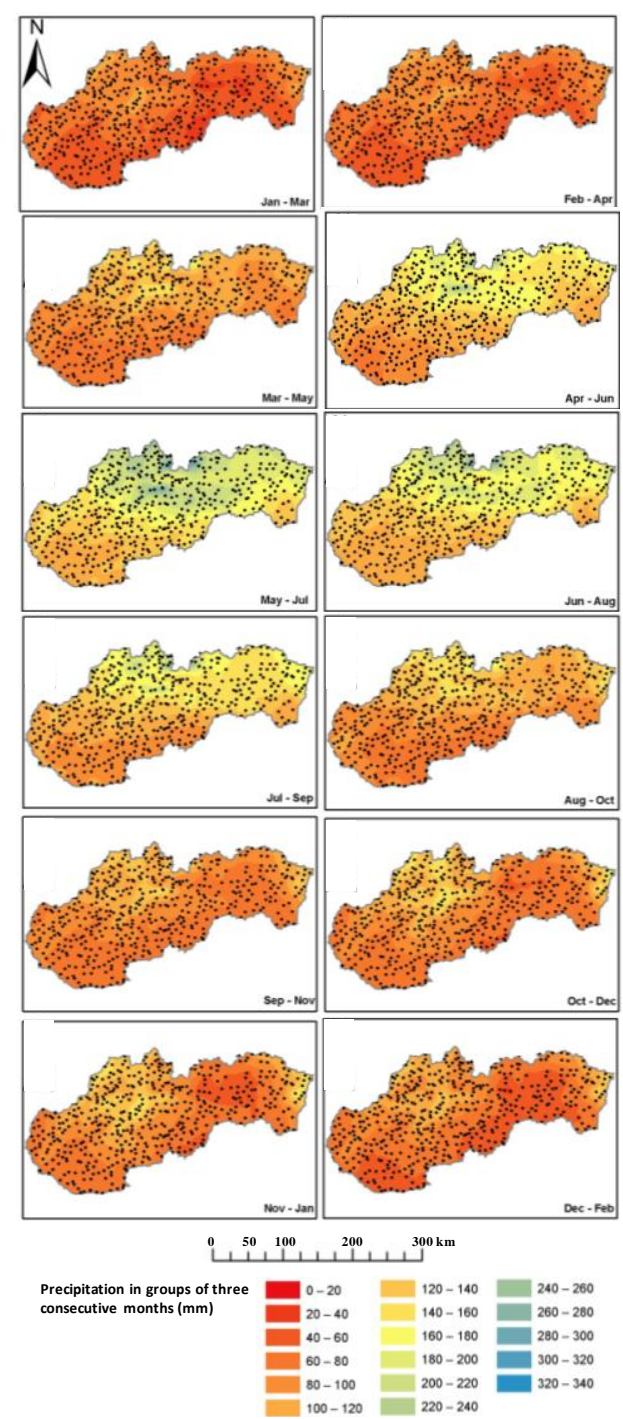

Fig. 5. Inversion of SPI3=-1.28 (severe drought). Precipitation in 3 consecutive months (identified in each map) corresponding to the severe drought threshold. Adapted from [2].

Each map of the Fig. 5 and 6 shows the spatial distribution of the cumulative precipitation in periods of three consecutive months such if the precipitation registered in a given location falls below the value given by the map for that location, then a severe/extreme drought is occurring.

The figures show that the spatial patterns of the threshold precipitations are poorly differentiated across the maps. However, the smooth transition between successive maps is easily understandable because each two consecutive maps always include a common period of analysis of two months.

Maps such as the ones of Fig. 5 and 6 and eventually for other time scales and droughts categories can be particularly suitable as tools of observatory and early warning systems of droughts. In fact, by comparing the registered precipitation in a given location and period with the precipitation thresholds for the same location, either for that period or for a wider one, 
obtained by including the following months, it is possible to conclude not only if a drought is occurring in that location but also how much it should rain in the next month/months in order to avoid drought conditions. By assigning probabilities to these amounts of rain it is possible to estimate the probabilities of recovering from a drought in the next months. Based on this information different decisions can be taken regarding the exploitation, for example, of water supply systems based on artificial reservoirs.
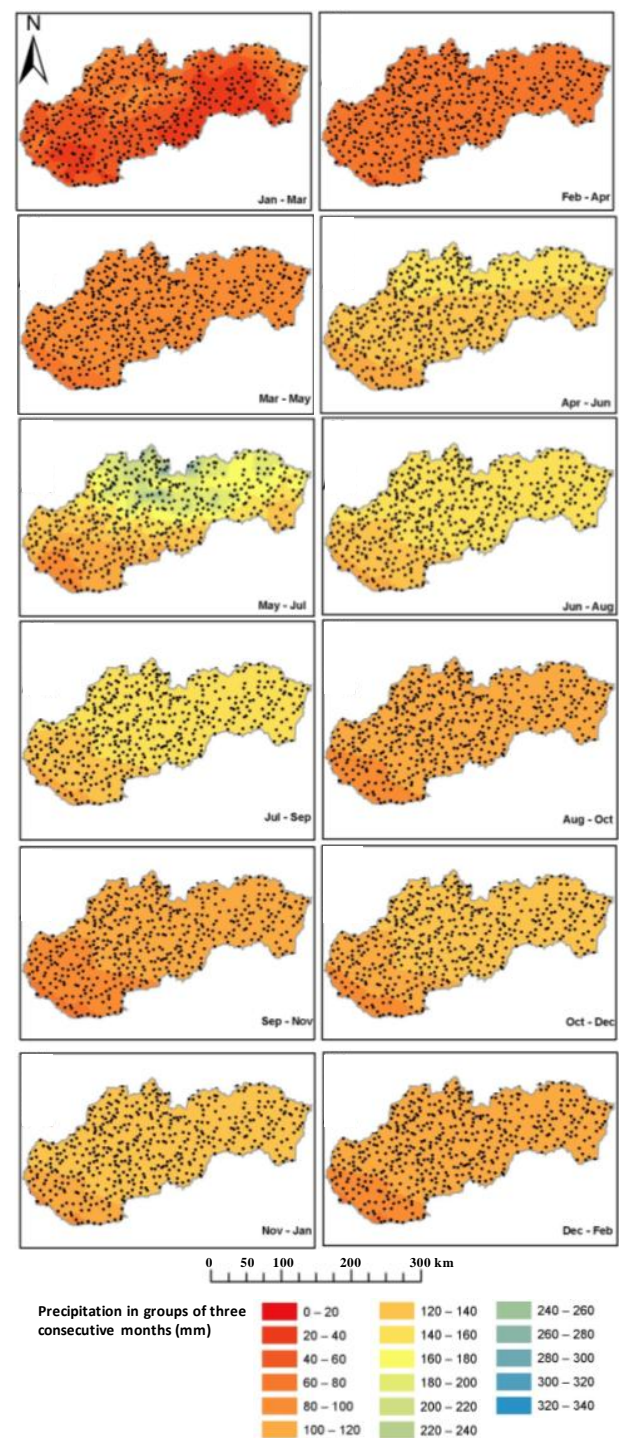

Fig. 6. Inversion of SPI3=-1.64 (extreme drought). Precipitation in 3 consecutive months (identified in each map) corresponding to the extreme drought threshold.

\section{CONCLUSIONS}

This paper presents a comprehensive characterization of the droughts for the entire Slovakia by using the Standardized Precipitation Index, SPI, computed based on a monthly precipitation dataset over a time-span of 33 years (from January 1981 to December 2013) at 491 rain gauges covering the entire country. Taking into account the relevance of agricultural in Slovakia, the time scale of three months, SPI3, was adopted to exemplify the results.

The regionalization analysis based on Principal Component Analysis applied to the SPI3 field resulted in the identification of four non-overlapping regions, homogeneous in terms of the temporal patterns of the drought events: Western, Central Northern, Eastern and Central Southern Slovakia. The characterization of the yearly frequency of droughts showed that, except for Central Northern region, all the other three regions experienced more frequent droughts in the past. Hence, there is no evidence that the droughts became more frequent in Slovakia, which somehow disagrees with the expected effects of the climate change. By inversion of the SPI3, surfaces of precipitation thresholds were obtained aiming at recognizing the drought occurrences in their early stages of development and at quantifying the probability of recovering from those events thus contributing to the sustainable management of the water resources, especially when based on artificial reservoirs.

Globally, the results achieved can provide guidance for drought risk assessment in Slovakia, as well as support information to improve water resources management, especially in the agricultural production sector. However additional studies are always required, for instance, by considering other time scales for the SPI and or other drought indices.

\section{REFERENCES}

[1] L. M. Tallaksen and H. A. Lanen, "Hydrological drought: processes and estimation methods for streamflow and groundwater," Developments in Water Science, vol. 48, Elsevier Science Limited, 2004.

[2] M. M. Portela, M. Zelenáková, J. F. Santos, P. Purcz, A. T. Silva, and H. Hlavatá, "Drought analysis in Slovakia: regionalization, frequency analysis and precipitation thresholds," presented at 8th International Conference on River Basin Management including all aspects of Hydrology, Ecology, Environmental Management, Flood Plains and Wetlands, RBM15, Wessex Institute, New Forest, UK, 2015.

[3] M. M. Portela, M. Zelenáková, J. F. Santos, P. Purcz, A. T. Silva, and H. Hlavatá, "Application of the SPI to the drought analysis in Slovakia. Drought regionalization and temporal evolution of the drought area," presented at 9th World Congress of EWRA. European Water Resources Association (EWRA), Istanbul, Turkey, 2015.

[4] T. B. McKee, N. J. Doesken, and J. Kleist, "The relationship of drought frequency and duration to time scales," in Proc. the 8th Conference on Applied Climatology, American Meteorology Society, pp. 179-184, 1993.

[5] J. F. Santos, I. Pulido-Calvo, and M. M. Portela, "Spatial and temporal variability of droughts in Portugal," Water Resources Research, vol. 46, 2010.

[6] J. Bazrafshan, S. Hejabi, and J. Rahimi, "Drought monitoring using multivariate standardized precipitation index," Water Resources Management, vol. 28, no. 4, pp. 1045-1060, 2014.

[7] Y. He, J. Ye, and X. Yang, "Analysis of the spatio-temporal patterns of dry and wet conditions in the Huai River Basin using the standardized precipitation index," Atmospheric Research, vol. 166, pp. 120-128, 2015.

[8] D. A. Wilhite and M. H. Glantz, "Understanding the drought phenomenon: The role of definitions," Water International, vol. 10, no. 3, pp. 111-120, 1985.

[9] FAO. (2006). Food and Agriculture Organization of the United Nations. [Online]. Available: http://apps.fao.org/

[10] S. M. Vicente-Serrano, "Las Sequías Climáticas en el Valle Medio del Ebro," Factores Atmosféricos, Evolución Temporal y Variabilidad Espacial, vol. 49, 2005.

[11] C. T. Agnew, "Using the SPI to identify drought," Drought Network News, vol. 12, pp. 6-12, 2000.

[12] OECD, "Organisation for economic co-operation and development," Water and Climate Change Adaptation: Policies to Navigate Uncharted Waters, OECD Studies on Water. OECD Publishing, 2013.

[13] R. S. Kovats et al., Climate Change 2014: Impacts, Adaptation, and Vulnerability. Part B: Regional Aspects. Contribution of Working Group II to the Fifth Assessment Report of the Intergovernmental Panel on Climate Chang, Cambridge University Press, Cambridge, United Kingdom and New York, NY, USA, pp. 1267-1326, 2014.

[14] A. Machlica, M. Stojkovova, and M. Fendekova, "Assessment of hydrological drought occurrence in Nitra River catchment (Slovakia) in the period 1976-2005," EGU General Assembly 2008, 2008. 
[15] J. Oosterwijk et al., "Hydrological drought characteristics of the Nedozery sub catchment, upper Nitra, Slovakia, based on HBY modeling," Technical Report, WATCH - Water and Global Change, 2009.

[16] B. Šiška and J. Takáč, "Drought analysis of agricultural regions as influenced by climatic conditions in the Slovak Republic," Idöiárás: Quarterly Journal of the Hungarian Meteorological Service, vol. 113, no. 1-2, pp. 135-143, 2009.

[17] P. Faško et al., "Trends of selected characteristics of precipitation in the northern Carpathians in the light of water supply for agriculture," Impact of Climate Change and Adaptation in Agriculture. Extended abstracts of the International Symposium, 2009.

[18] U. Büngten et al., "Three centuries of Slovakina drought dynamics," Climate Dynamics, vol. 35, pp. 315-329, 2010.

[19] G. Miloš, "Analysis of hydrological drought," In Surface and Groundwater Quality Changes in Periods of Water Scarcity, Springer Theses 2013, 2012

[20] J. Vido et al., "Drought occurrence in Central European mountainous region (Tatra National Park - Slovakia) within the period 1961-2010," Advances in Meteorology, Hindawi Publishing Corporation, 2015.

[21] B. Bonaccorso et al., "Spatial variability of drought: An analysis of the SPI in sicily," Water Resources Management, vol. 17, pp. 273-296, 2003.

[22] S. M. Vicente-Serrano et al., "Drought patterns in the Mediterranean area: The Valencia region (eastern Spain)," Climate Research, vol. 26, pp. 5-15, 2004

[23] F. B. Bryant and P. R. Yarnold, "Principal-components analysis and confirmatory factor analysis," Reading and Understanding Multivariate Statistics, Washington, DC: American Psychological Association, 1995.

[24] M. Mudelsee et al., "No upward trends in the occurrence of extreme floods in central Europe," Nature, vol. 425, pp. 166-169, 2003.

[25] A. T. Silva et al., "Nonstationarities in the occurrence rates of flood events in Portuguese watersheds," Hydrology and Earth System Sciences, vol. 16, no. 1, pp. 241-254, 2012.

[26] M. M. Portela et al., "Chapter 3. Analysis of temporal variability of droughts in southern Paraguay and Northern Argentina (1961-2011)," International Perspectives on Climate Change, Springer International Publishing Switzerland, pp. 31-46, 2014.

[27] M. M. Portela et al., "Drought analysis in southern Paraguay, Brazil and northern Argentina: regionalization, occurrence rate and precipitation thresholds," Hydrology Research, vol. 46, no. 5, pp. 792-810, 2015.

[28] P. Diggle, "A kernel method for smoothing point process data. Royal statistical society," Applied Statistics, vol. 34, no. 2, pp. 138-147, 1985.

[29] M. Mudelsee et al., "Extreme floods in central Europe over the past 500 years: role of cyclone pathway Zugstrasse Vb," Journal of Geophysical Research, 2004.

[30] A. Cowling et al., "Bootstrap confidence regions for the intensity of a Poisson point process," Journal of the American Statistical Association vol. 91, no. 436, pp. 1516-1524, 1996.

[31] M. Mudelsee, "The bootstrap in climate risk analysis," Extremis: Disruptive Events Trends in Climate and Hydrology, pp. 45-58, Springer, 2011.

[32] A. H. Thiessen, "Precipitation averages for large areas," Monthly Weather Review, vol. 39, pp. 1082-1084, 1911.

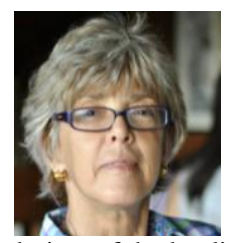

Maria Manuela Portela is Ph.D in civil engineering. She is an associate professor with habilitation at the Civil Engineering Department of Lisbon's Instituto Superior Técnico (IST), Portugal. As consultant and researcher she has more than 30 years of experience in hydrology, surface water resources and hydrological modeling, statistical and mathematical approaches and design of hydraulic infra-structures. She has more than 180 papers in international and national journals and conferences.

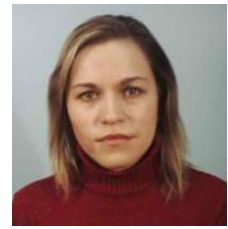

Martina Zeleňáková is associated professor at Institute of Environmental Engineering at Civil Engineering Faculty, Technical University of Košice, Slovakia. The field of her scientific-research work is water management and environmental risks. The results from her work are published in journals and scientific proceedings from Slovak and abroad conferences.

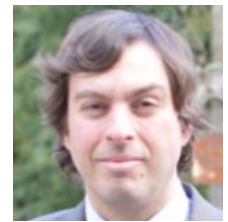

João Santos is a Ph.D. in Civil Engineering. He is a professor adjunct in the Polytechnic Institute of Beja, Portugal. He has some foreign lecturing experience in Poland, Lithuania and Slovakia. As a consultant engineer he has been gaining experience since 2004 , both nationally and abroad in the areas of hydrologic modelling, planning of water resources and hydraulic systems. He has been publishing in national and international referee journals and conferences.

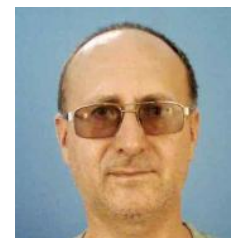

Pavol Purcz is assistant professor at Institute of Construction Technology and Management at Civi Engineering Faculty, Technical University of Košice, Slovakia. He teaches mathematics and is interested in the field of mathematical statistic in climatic and hydrological time series.

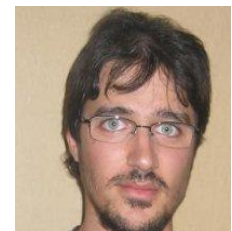

Artur Tiago Silva is a Ph.D candidate in civil engineering and researcher in hydrology at Lisbon's Instituto Superior Técnico, Portugal. He is developing research on the risk of hydrological extremes, such as floods and extreme rainfall events. The main focus is on methodologies that explicitly allow for nonstationarity in the statistical modelling of hydrological extremes and on the application of such methods in hydrological practice and science.

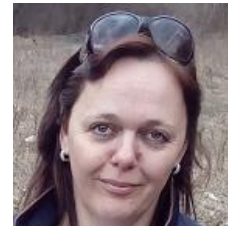

Helena Hlavatá works as meteorologist, climatologist specialist at the Slovak Hydrometeorological Institute in Košice, Department of Meteorological Service. Her scientific research is devoted to the analysis of precipitation and runoff. The results thus achieved have been presented at several conferences and seminars. 